\title{
Wear Mechanism of Wear Resistant HVOF Thermal Spray Coating: Chromium Carbide Nickel Chrome on 304 AISI Steel
}

\author{
Muhamad Harith Izdiyad Sidik ${ }^{1}, N$. Amir ${ }^{1,}$, Subhash Kamal ${ }^{2}$ \\ ${ }^{1}$ Mechanical Engineering Department, Universiti Teknologi PETRONAS, 32610 Bandar Seri \\ Iskandar, Perak, Malaysia. \\ ${ }^{2}$ Department of Mechanical Engineering, ZCOER, Narhe, Pune, Maharashtra 411041, India
}

\begin{abstract}
One of the common ways to overcome wear is by surface modification which is a coating process. The application of cermet of chromium (Cr carbide) in Nickel-Chromium (Ni-Cr) matrix is widely used as coating material since it provides high wear resistant. Besides, thermal spray process is widely known as the most suitable technique to produce cermet coating. In this study, chromium carbide-nickel chrome $\left(\mathrm{Cr}_{3} \mathrm{C}_{2}-\right.$ $\mathrm{NiCr}$ ) powder is used as the feedstock. High Velocity Oxy Fuel (HVOF) thermal spraying is used to deposit the coating on mild steel substrate to study the behaviour of wear of the coating. The wear test is conducted by using TABER Linear Abrasion Wear Test machine. The wear rate of both coated and uncoated pin is measured by measuring the weight loss of the samples. The $\mathrm{Cr}_{3} \mathrm{C}_{2}-\mathrm{NiCr}$ coated pins have shown less weight loss than the uncoated pins. The lifetime prediction of $\mathrm{Cr}_{3} \mathrm{C}_{2}-\mathrm{NiCr}$ coated pins is higher than the uncoated pins at different time duration and applied loads. The results showed that the wear resistant properties of $\mathrm{Cr}_{3} \mathrm{C}_{2}-\mathrm{NiCr}$ coated pins are higher than the uncoated pins. Scanning Electron Microscopic (SEM) integrated with Energy-dispersive X-ray spectroscopy (EDS) are used to determine the microstructure of $\mathrm{Cr}_{3} \mathrm{C}_{2}-\mathrm{NiCr}$ coating. The microstructure of $\mathrm{Cr}_{3} \mathrm{C}_{2}-\mathrm{NiCr}$ coated pin after the wear testing showed no presence of crack and the wear track was homogenous.
\end{abstract}

\section{Introduction}

Nowadays, wear of material have been a crucial problem to every country as it results high economic loss. However, there are ways to overcome the wear related problem for examples, using high-cost wear resistant material or doing some modification or alteration to the surface contact of the material such as using coating. According to [1] Chromium Carbide - Nickel Chrome $\left(\mathrm{Cr}_{3} \mathrm{C}_{2}-\mathrm{NiCr}\right)$ material are widely used in the production of hard coating in high temperature application $\left(800^{\circ} \mathrm{C}\right)$. The reason is this material are resistant to high temperature and corrosion. Due to the high melting point, $\mathrm{Cr}_{3} \mathrm{C}_{2}-\mathrm{NiCr}$ coating provides high oxidation.

Thermal spray is a technique of surface modification to increase the properties of the surface itself. There are many thermal spray processes for examples, flame spraying, high

\footnotetext{
*Corresponding author: norlailiamir@utp.edu.my
} 
velocity oxy fuel (HVOF) and plasma spraying. They are widely used by deposited coating material to the surface of the material as to increase the wear resistance. Plasma spraying and HVOF are considered as the most suitable process to produce high wear resistance coating. HVOF exhibits high density, low porosity and bond strength.

The process of coating involves thermal spray coating which is using heat in highly temperature as source. Based on [2] thermal spray coating especially applied through HVOF, can deposit on wide range of materials for the use in oil and gas application with high mechanical and chemical properties and cheaper compared to the overlay welding technique. In fact there are other thermal spray techniques i.e. plasma spray, detonation and flame spraying; HVOF is considered the cheapest process.

Wear is a progressive loss material from contacting surface relative in motion. So, as the two surface of material is rubbing together, there is some loss in material resulting one of the material will damage depends on its wear resistance. In automotive industry, the $\mathrm{Cr}_{3} \mathrm{C}_{2}-\mathrm{NiCr}$ coating has been widely used especially for the piston in engine $\mathrm{Cr}_{3} \mathrm{C}_{2}-\mathrm{NiCr}$ coating can prolong the life of the piston as it is very useful in high temperature condition. Basically, the wear rate can be analysed by wear test using Linear Abrasions Wear Test machine.

For engineering, wear mechanism is not something new. When there are two surface of material is colliding or contacting, there will be a wear. Wear can bring a lot of trouble to the machine or mechanism itself. In engine itself when there is a wear in piston, it will result the piston not function well. This is due to the leaking of the air and thus it will minimize the power of the engine. Even in piping, there is many erosion and corrosion have been major issues in oil exploration as during exploration phase, for example drilling in crude oil and slurries, when wear of material such as drilling tools and pipes may occur. If there is too high wear rate, it is possible that the mechanism will damage and brings a lot of loss in term of money, time and effort. Moreover, for $\mathrm{Cr}_{3} \mathrm{C}_{2}-\mathrm{NiCr}$ coating in various load, wear test have not been done so far. Hence, this project will focus on the wear resistant of thermal spray coating which is using HVOF process.

The objectives of this project are to estimate the lifetime of thermal spray coating, $\mathrm{Cr}_{3} \mathrm{C}_{2}-$ $\mathrm{NiCr}$ on mild steel pin and also to measure the wear rate of the $\mathrm{Cr}_{3} \mathrm{C}_{2}-\mathrm{NiCr}$ coating. The study of the microstructure of $\mathrm{Cr}_{3} \mathrm{C}_{2}-\mathrm{NiCr}$ coating before and after wear test are also carried out. Furthermore, in this project the pin is tested under various load and total cycles.

\section{Materials and methodology}

\subsection{Materials selection}

304 AISI mild steel was used as the base material before the coating process. Chromium Carbide - Nickel Chrome $\left(\mathrm{Cr}_{3} \mathrm{C}_{2}-\mathrm{NiCr}\right)$ was used as the coating material during the process of HVOF. The coating process was done at Metatech Sdn. Bhd. located at Shah Alam, Selangor.

\subsection{Sample preparation}

For this project, $\mathrm{Cr} 3 \mathrm{C} 2-\mathrm{NiCr}$ powder was used as the feedstock. HVOF thermal spraying as illustrated in Figure 1 was used to deposit the powder on substrate with an aimed thickness of approximately, $100 \mu \mathrm{m}$. Before the deposition process, the surface of substrate was sand blasted using aluminium oxide (A12O3) at a pressure of 40 psi for surface cleaning and roughening. 


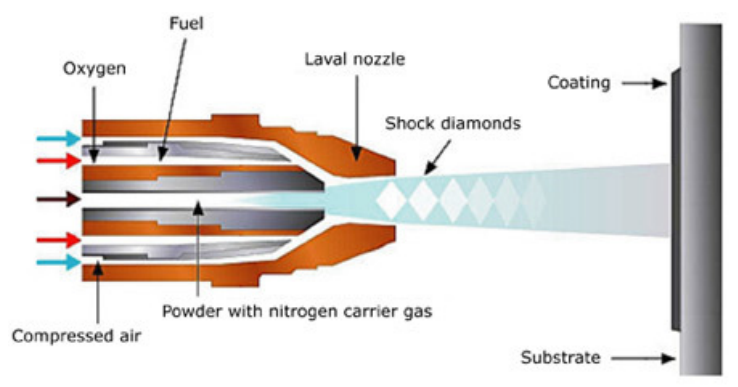

Fig. 1. HVOF Thermal Spray Coating [8].

\subsection{Wear test}

Wear test was conducted using Standard Test Method for Pin Abrasion Testing, G132-96.

The Taber Linear Abrasion machine as Figure 2 is switched on and as is calibrated for each cycle per minutes. All the sample is weighted before the test was run. Using the lock mechanism, the collect assembly is locked in the 'up' position. The stroke length is set to $25.4 \mathrm{~mm}$. The mode is switched to 'run'. The counter is set to the desired number of cycles and speed of the cycles per minute using the numerical keypad, while the weights are added manually. Table 1 shows the experiment's controlled variable setup for both Test 1 and Test 2.

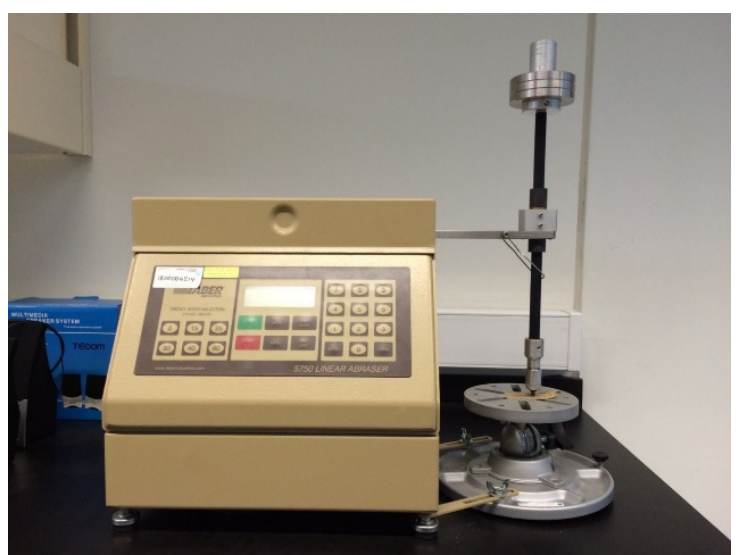

Fig. 2. Taber Linear Abrasion Machine

Table 1. Variables for Test 1 and Test 2 setup.

\begin{tabular}{|l|l|l|}
\hline Parameters & Test $\mathbf{1}$ & Test 2 \\
\hline $\begin{array}{l}\text { Stroke length } \\
(\mathbf{m m})\end{array}$ & 25.4 & 25.4 \\
\hline Speed & 30 cycles per min & 30 cycles per min \\
\hline & 3.5 & 6.0 \\
Weight (N) & 6.0 & \\
\hline & 8.5 & 100 \\
Time (s) & 400 & 200 \\
& & 400 \\
\hline
\end{tabular}

A strip of 180 grit sand paper is attached on the flat table, with the samples secured within the abrasion path. The samples are properly set up in the collect. The start button is pressed to run the test. When the test is complete, the lock mechanism is used to lock again the collect 
assembly in the 'up' position. The pin sample is removed from the collect and is weighted using precision balance. The weight loss of sample is calculated to analyse the wear rate of the sample. The test was conducted for both coated and uncoated pin to analyse the life cycle of the $\mathrm{Cr}_{3} \mathrm{C}_{2}-\mathrm{NiCr}$ coating.

\section{Results discussion}

\subsection{Wear test}

Two experiments were run in mechanical laboratory with different variables. These variables are the time and loads. Experimental result i.e. weight loss from the wear test for both coated and uncoated $\mathrm{Cr}_{3} \mathrm{C}_{2}-\mathrm{NiCr}$ pin was obtained by using Taber Linear Abrasion. The whole result were taken, calculated and tabled.

As to calculate the percentage of weight loss, Equations (1) to (2), are used. The calculation were done step by step for accuracy purpose.

Equation of weight loss in gram,

$$
\text { Weight loss }(g)=\text { Initial weight }(g) \text {-Final weight }(g)
$$

Equation of weight loss in percentage,

$$
\begin{aligned}
& \text { Weight loss }(\%)=(\text { Initial weight }(g)-\text { Final weight }(g)) /(\text { Initial } \\
& \text { weight }(g)) \times 100
\end{aligned}
$$

For the Test 1 setup, the result obtained for the weight loss was tabulated in Table 2.

Table 2. Weight loss for the wear test under different total time.

\begin{tabular}{|l|l|l|l|l|l|}
\hline \multicolumn{2}{|c|}{ Condition } & \multicolumn{2}{c|}{$\mathrm{Cr}_{3} \mathrm{C}_{2}-\mathrm{NiCr}$ coated pin } & \multicolumn{2}{c|}{ Uncoated pin } \\
\hline Sample & Load (N) & Weight loss (g) & Weight loss (\%) & Weight loss (g) & Weight loss (\%) \\
\hline Pin 1 & 100 & 0.0003 & 0.0130 & 0.0005 & 0.0219 \\
\hline Pin 2 & 200 & 0.0005 & 0.0216 & 0.0011 & 0.0481 \\
\hline Pin 3 & 400 & 0.0009 & 0.0389 & 0.0017 & 0.0744 \\
\hline
\end{tabular}

For the Test 2 setup, the results obtained for the weight loss was tabulated in the Table 3.

Table 3. Weight loss for the wear test under the different loads.

\begin{tabular}{|l|l|l|l|l|l|}
\hline \multicolumn{2}{|c|}{ Condition } & \multicolumn{2}{c|}{$\mathrm{Cr}_{3} \mathrm{C}_{2}-\mathrm{NiCr}$ coated pin } & \multicolumn{2}{c|}{ Uncoated pin } \\
\hline Sample & Load (N) & Weight loss (g) & Weight loss (\%) & Weight loss (g) & Weight loss (\%) \\
& & & & & \\
\hline Pin 1 & 3.5 & 0.0003 & 0.0124 & 0.0035 & 0.1431 \\
\hline Pin 2 & 6.0 & 0.0004 & 0.0162 & 0.0068 & 0.2784 \\
\hline Pin 3 & 8.5 & 0.0014 & 0.0570 & 0.0112 & 0.4598 \\
\hline
\end{tabular}


Figure 3 shows the comparison of percentage weight loss versus total times by using different $\mathrm{Cr}_{3} \mathrm{C}_{2}-\mathrm{NiCr}$ coated and uncoated pin. Both curves show that the relationship of independent variable was directly proportional to the dependant variable. in the other words, increasing the total times from $100 \mathrm{~s}$ to $400 \mathrm{~s}$ will increase the percentage weight loss of the pin.

For the $\mathrm{Cr}_{3} \mathrm{C}_{2}-\mathrm{NiCr}$ coated pin, the value of the percentage weight loss increased consistently where the differences of the value were in control. Moreover, $\mathrm{Cr}_{3} \mathrm{C}_{2}-\mathrm{NiCr}$ coated pin clearly shown that it gives the lower value of percentage weight loss than the uncoated pin. The lowest value of the percentage weight loss obtained for $\mathrm{Cr}_{3} \mathrm{C}_{2}-\mathrm{NiCr}$ coated pin was $0.013 \%$, while for uncoated pin was $0.0219 \%$ at the $100 \mathrm{~s}$ total times. So, the value of $0.013 \%$ clearly shows that the $\mathrm{Cr}_{3} \mathrm{C}_{2}-\mathrm{NiCr}$ coated pin is more resistance to wear than the uncoated pin. This shows that the $\mathrm{Cr}_{3} \mathrm{C}_{2}-\mathrm{NiCr}$ coating gives a great impact to the surface of the pin as to resist the wear.

Figure 4 shows the comparison of percentage weight loss versus loads by using different $\mathrm{Cr}_{3} \mathrm{C}_{2}-\mathrm{NiCr}$ coated and uncoated pin. The same pattern of the graph obtained with the total times. The both graph shown that the relationship of independent variable was directly proportional to the dependant variable. Thus, increasing the loads from $350 \mathrm{~g}$ to $850 \mathrm{~g}$ increased the percentage weight loss of the pin. This is supported by [9] which said that at room temperature, the wear rate of the both coated and uncoated sample increase with the increasing load. For the $\mathrm{Cr}_{3} \mathrm{C}_{2}-\mathrm{NiCr}$ coated pin, the value of the percentage weight loss increased consistently where the differences of the value were in control.

Moreover, $\mathrm{Cr}_{3} \mathrm{C}_{2}-\mathrm{NiCr}$ coated pin clearly shown that it gives the lowest value of percentage weight loss rather than uncoated pin. The lowest value of the percentage weight loss that was obtained $\mathrm{Cr}_{3} \mathrm{C}_{2}-\mathrm{NiCr}$ coated pin was $0.0124 \%$ at the $350 \mathrm{~g}$ loads while uncoated pin was $0.1431 \%$ at the $350 \mathrm{~g}$ loads. Thus, the value of $0.0124 \%$ clearly shows that the $\mathrm{Cr}_{3} \mathrm{C}_{2}$ $\mathrm{NiCr}$ coated pin is more resistance to wear rather than to uncoated pin. The differences the percentage weight loss between $\mathrm{Cr}_{3} \mathrm{C}_{2}-\mathrm{NiCr}$ coated and uncoated pin at the $350 \mathrm{~g}$ loads is high as the load gives a great effect to the uncoated pin while it is slightly to the $\mathrm{Cr}_{3} \mathrm{C}_{2}-\mathrm{NiCr}$ coated pin.

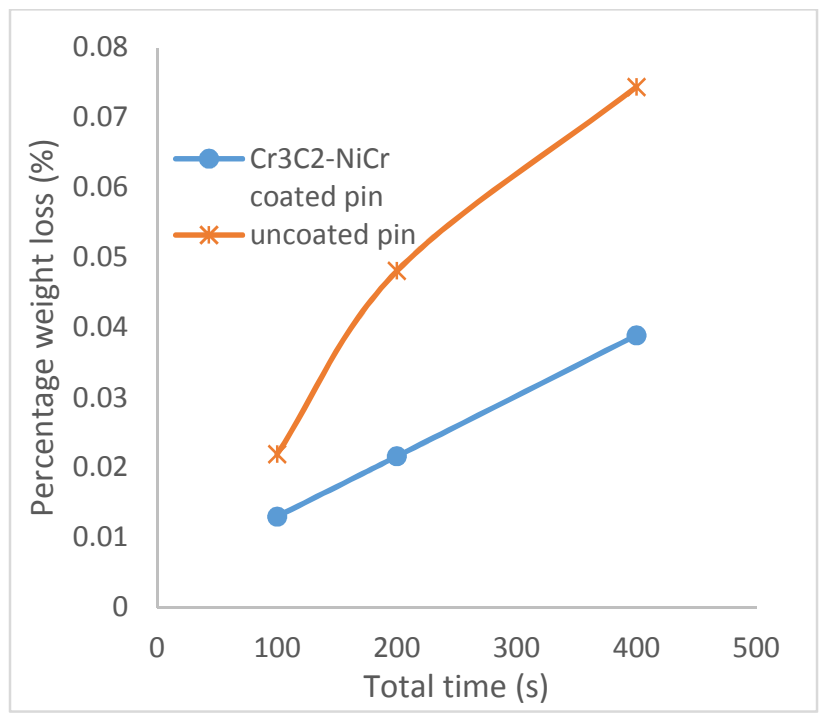

Fig. 3. Comparison of Percentage Weight Loss versus Total Time for $\mathrm{Cr} 3 \mathrm{C} 2-\mathrm{NiCr}$ coated and uncoated pin. 


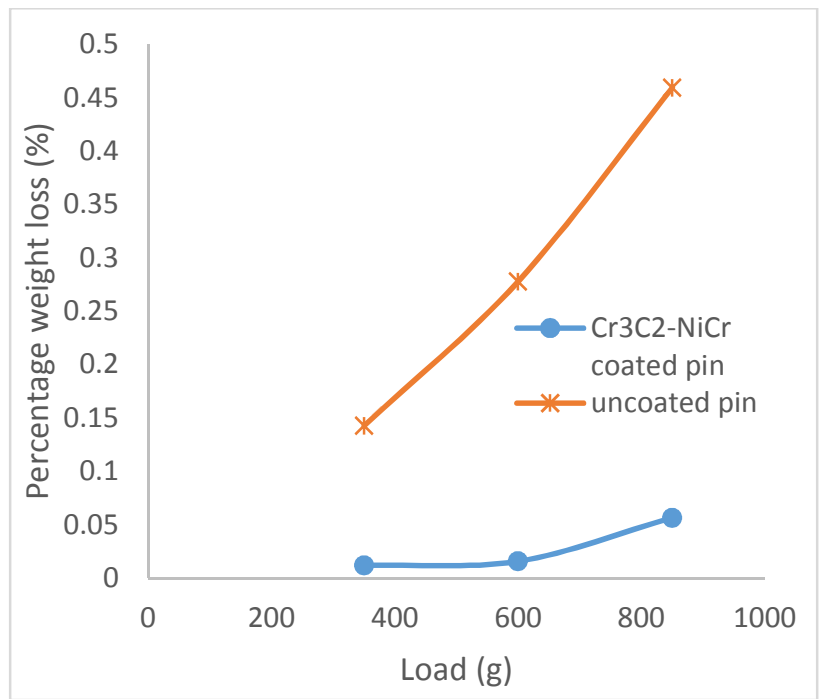

Fig. 4. Comparison of Percentage Weight Loss versus Load for $\mathrm{Cr} 3 \mathrm{C} 2-\mathrm{NiCr}$ coated and uncoated pin.

\subsection{The lifetime of the Cr3C2-NiCr coating}

The lifetime of the $\mathrm{Cr}_{3} \mathrm{C}_{2}-\mathrm{NiCr}$ coating can be estimate or measure as the result from this experiment. The result obtained from the relationship between the weight loss and total time can be analysed and calculated to predict the lifetime of the $\mathrm{Cr}_{3} \mathrm{C}_{2}-\mathrm{NiCr}$ coating. Based on the Table 4, the weight loss of $\mathrm{Cr}_{3} \mathrm{C}_{2}-\mathrm{NiCr}$ coated pin at $100 \mathrm{~s}$ is $0.0003 \mathrm{~g}$ and for the uncoated pin, the weight loss is $0.0005 \mathrm{~g}$ at $100 \mathrm{~s}$. To predict the lifetime of the $\mathrm{Cr}_{3} \mathrm{C}_{2}-\mathrm{NiCr}$ coating, the formula is stated in Equation (3).

Assumption for $200 \mathrm{~g}$ weight loss,

$$
\text { lifetime, } s=\frac{200 \mathrm{~g}}{\text { Weight loss }} \times \text { total time }
$$

For uncoated pin,

Weight loss $=0.0005 \mathrm{~g}$ at $100 \mathrm{~s}$ total times

lifetime, $s=\frac{200 \mathrm{~g}}{0.0005} \times 100$

lifetime, $s=4 \times 10^{7}$ second

For $\mathrm{Cr}_{3} \mathrm{C}_{2}-\mathrm{NiCr}$ coated pin,

Weight loss $=0.0003 \mathrm{~g}$ at $100 \mathrm{~s}$ total times

lifetime, $s=\frac{200 \mathrm{~g}}{0.0003} \times 100$

lifetime, $s=6.67 \times 10^{7}$ second

From the Equation 2, the lifetime of the $\mathrm{Cr}_{3} \mathrm{C}_{2}-\mathrm{NiCr}$ coated and uncoated pin can be obtained. Table 4 shows that the conversion time from second to years for $\mathrm{Cr}_{3} \mathrm{C}_{2}-\mathrm{NiCr}$ coated and uncoated pin. The lifetime for $\mathrm{Cr}_{3} \mathrm{C}_{2}-\mathrm{NiCr}$ coated pin under assumption for $200 \mathrm{~g}$ is 2.11 years while for uncoated pin is 1.27 . These result obtained clearly shows that the $\mathrm{Cr}_{3} \mathrm{C}_{2}-\mathrm{NiCr}$ coated pin have longer lifetime rather than uncoated pin. This result obtained also indicate that the wear resistant of $\mathrm{Cr}_{3} \mathrm{C}_{2}-\mathrm{NiCr}$ coated pin is higher than uncoated pin as the lifetime of $\mathrm{Cr}_{3} \mathrm{C}_{2}-\mathrm{NiCr}$ coated pin is higher than uncoated pin. 
Table 4. Conversion time from second to years for lifetime $\mathrm{Cr} 3 \mathrm{C} 2-\mathrm{NiCr}$ coated and uncoated pin.

\begin{tabular}{|l|l|l|l|l|}
\hline Time & Seconds & Hours & Days & Years \\
\hline $\begin{array}{l}\mathrm{Cr}_{3} \mathrm{C}_{2}-\mathrm{NiCr} \\
\text { coated pin }\end{array}$ & $6.67 \times 10^{7}$ & 18518.52 & 772 & 2.11 \\
\hline $\begin{array}{l}\text { Uncoated } \\
\text { pin }\end{array}$ & $4.00 \times 10^{7}$ & 11111.11 & 463 & 1.27 \\
\hline
\end{tabular}

Moreover, the lifetime of the coating in different load also have been analysed. Based on the Table 4, the lifetime of the coating in $3.5 \mathrm{~N}, 6 \mathrm{~N}$ and $8.5 \mathrm{~N}$ have been calculated and tabulated in the Table 5. The calculation is based on the assumption of $200 \mathrm{~g}$ of weight loss.

Predicted time for $200 \mathrm{~g}$ of coated powder to wear completely under $350 \mathrm{~g}$ load:

$=\frac{200 \mathrm{~g} \text { of coated powder }}{\text { Weight loss of coated powder }(\mathrm{g})} \times$ Cycle time $(s)$

$=\frac{200 \mathrm{~g}}{0.0003 \mathrm{~g}} \times 400(\mathrm{~s})$

$=2.67 \times 10^{8} \mathrm{~s}$

$\approx 8.5$ years

Predicted time for $200 \mathrm{~g}$ of coated powder to wear completely under $850 \mathrm{~g}$ load:

$=\frac{200 \mathrm{~g}}{0.0014 \mathrm{~g}} \times 400(\mathrm{~s})=5.71 \times 10^{7} \mathrm{~s}$

$\approx 2$ years

Predicted time for $200 \mathrm{~g}$ of uncoated pin to wear under $350 \mathrm{~g}$ load:

$=\frac{200 \mathrm{~g} \text { of uncoated pin }}{\text { Weight loss of uncoated pin }(\mathrm{g})} \times$ Cycle time $(\mathrm{s})$

$=\frac{200 \mathrm{~g}}{0.0035 \mathrm{~g}} \times 400(\mathrm{~s})$

$=2.29 \times 10^{7} \mathrm{~s}$

$\approx 0.7$ years

Predicted time for $200 \mathrm{~g}$ of uncoated pin to wear under $850 \mathrm{~g}$ load:

$=\frac{200 \mathrm{~g} \text { of uncoated pin }}{\text { Weight loss of uncoated pin }(\mathrm{g})} \times$ Cycle time $(\mathrm{s})$

$=\frac{200 \mathrm{~g}}{0.0112 \mathrm{~g}} \times 400(\mathrm{~s})$

$=7.14 \times 10^{6} \mathrm{~s}$

$\approx 0.2$ years

These result obtained clearly shows that the $\mathrm{Cr}_{3} \mathrm{C}_{2}-\mathrm{NiCr}$ coated pin have longer lifetime rather than uncoated pin. This result obtained also indicate that the wear resistant of $\mathrm{Cr}_{3} \mathrm{C}_{2^{-}}$ $\mathrm{NiCr}$ coated pin is higher than uncoated pin as the lifetime of $\mathrm{Cr}_{3} \mathrm{C}_{2}-\mathrm{NiCr}$ coated pin is higher than uncoated pin.

Table 5. Lifetime prediction for the sample tested by different loads.

\begin{tabular}{|l|c|c|c|c|c|}
\hline \multirow{2}{*}{ Sample } & \multicolumn{2}{|l|}{ Experimental Results } & \multicolumn{2}{l|}{ Lifetime Prediction } \\
\cline { 2 - 6 } & Load (g) & Weight Loss (g) & Duration (s) & Weight Loss (g) & Duration (year) \\
\hline Coated & 350 & 0.0003 & 400 & 200 & 8.5 \\
\hline Uncoated & 350 & 0.0035 & 400 & 200 & 0.7 \\
\hline Coated & 850 & 0.0014 & 400 & 200 & 2.0 \\
\hline Uncoated & 850 & 0.0112 & 400 & 200 & 0.2 \\
\hline
\end{tabular}




\subsection{The microstructure analysis of the $\mathrm{Cr} 3 \mathrm{C} 2-\mathrm{NiCr}$ coating}

Scanning electron microscope (SEM) is commonly used instrument in materials characterization study. It has been used to observe the density, thickness and porosity of the coating by generating high-resolution images of shapes of objects with precise measurement of very small features and object down to $50 \mathrm{~nm}$ in size. Besides, it is found the observation on these properties of the coating will help the success of the characterization of the coating as it is important to understand the capability of the coating under applied various environments.

Figure 5 shows the microstructure of the $\mathrm{Cr}_{3} \mathrm{C}_{2}-\mathrm{NiCr}$ coating in magnification of $1000 \mathrm{x}$, 1500x and 3000x. Through this figure, it shows that the white areas indicate the metallic binding matrix while the darker areas indicate chrome carbides or oxides. This is supported by ref. [6]. There is some pore at the microstructure of the $\mathrm{Cr}_{3} \mathrm{C}_{2}-\mathrm{NiCr}$ coating which is appear in black colour. As supported by [1], the pores appears in black colour is due to the un-melted and semi-melted particles in the $\mathrm{Cr}_{3} \mathrm{C}_{2}-\mathrm{NiCr}$ coatings as identified by their spherical morphology. It can be considered as a low porosity value because of the high impact velocity of the $\mathrm{Cr}_{3} \mathrm{C}_{2}-\mathrm{NiCr}$ coating particles during $\mathrm{HVOF}$ process.
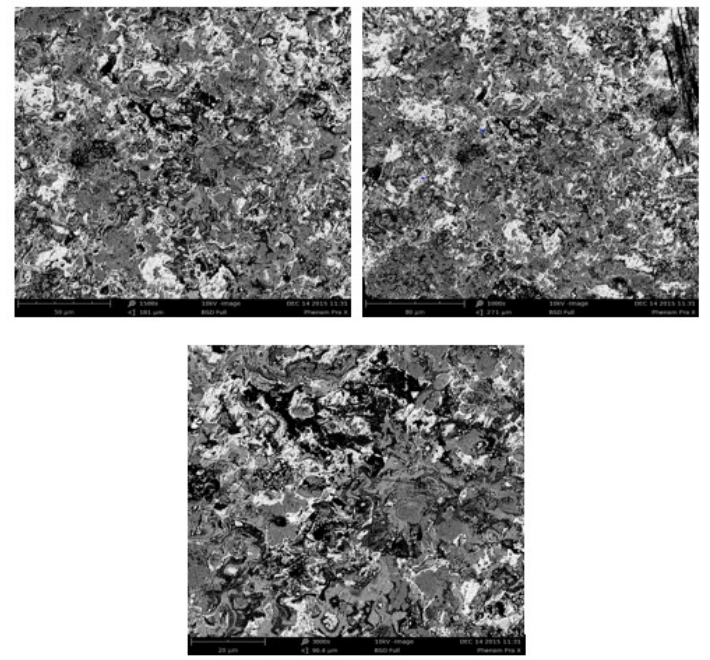

Fig. 5. The microstructure of $\mathrm{Cr} 3 \mathrm{C} 2-\mathrm{NiCr}$ coating before the test in magnification of 1000x, 1500x and $3000 \mathrm{x}$

The effect of the loads on the wear rate was studied via the microstructure of $\mathrm{Cr}_{3} \mathrm{C}_{2}-\mathrm{NiCr}$ coating after wear test with different loads. Figure 6 shows that the microstructure of $\mathrm{Cr}_{3} \mathrm{C}_{2^{-}}$ $\mathrm{NiCr}$ coating after wear test with different loads in the magnification of $1000 \mathrm{x}, 1500 \mathrm{x}$ and $3000 x$. Obviously, homogenous and smooth wear track appeared on surface of $\mathrm{Cr}_{3} \mathrm{C}_{2}-\mathrm{NiCr}$ coating. Figure 6 clearly shows that there are abrasion and the wear track is not very deep. Also, the presence of crack is not visible.

This is clearly supported by ref. [1], that stated no crack or deformation was created at the edge of the sample when the maximum load is applied. This was associated with the elevated bonding strength between the splats and components as well as the significant role that bond strength can play in splat propagation and resistance to crack initiation. However, in the Figure 7 for the study on the effect of cycle times, the wear track is not as deep as in Figure 6. This clearly shows that loads are given more effect to the surface of $\mathrm{Cr}_{3} \mathrm{C}_{2}-\mathrm{NiCr}$ coating compared to cycle times. 
Figure 8 shows the microstructure of $\mathrm{Cr}_{3} \mathrm{C}_{2}-\mathrm{NiCr}$ coating before the test with three different spots for EDS analysis. The spots were randomly chosen in finding the distribution of elements in the $\mathrm{Cr}_{3} \mathrm{C}_{2}-\mathrm{NiCr}$ coating.

Figure 9 shows the spectrum of every element in different spot at the top surface of $\mathrm{Cr}_{3} \mathrm{C}_{2}$ $\mathrm{NiCr}$ coating. The weight percentage of chrome is the highest at the spot 2 which is $100 \%$ compared to the spot 1 and spot 3 which is only $15.9 \%$ and $54.5 \%$, respectively. This indicates that the volume of chrome is high in the $\mathrm{Cr}_{3} \mathrm{C}_{2}-\mathrm{NiCr}$ coating. It can be observed that the morphology of the coating produced by the HVOF thermal spray is scattered around the substrate and formed mixed element on the coating.
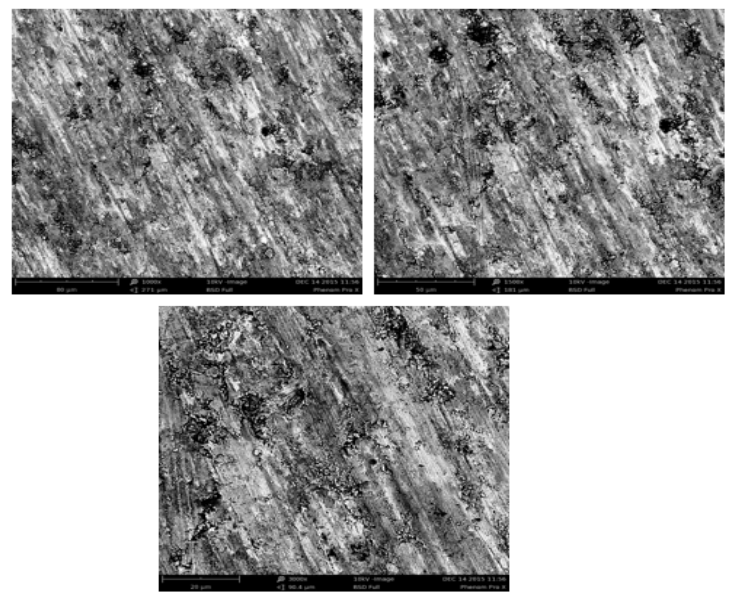

Fig. 6. The microstructure of $\mathrm{Cr} 3 \mathrm{C} 2-\mathrm{NiCr}$ coating after the test with the different load in magnification of 1000x, 1500x and 3000x.

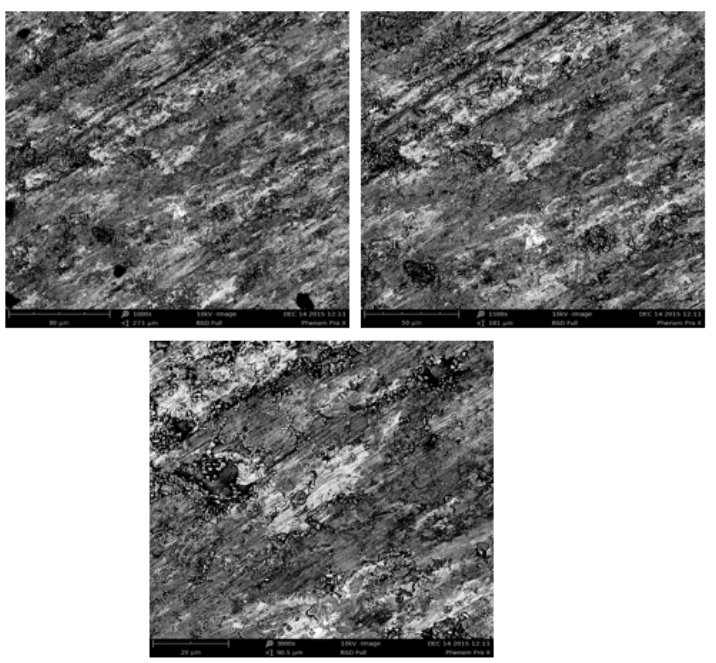

Fig. 7. The microstructure of $\mathrm{Cr} 3 \mathrm{C} 2-\mathrm{NiCr}$ coating after the test with the different time cycle in magnification of 1000x, 1500x and 3000x. 


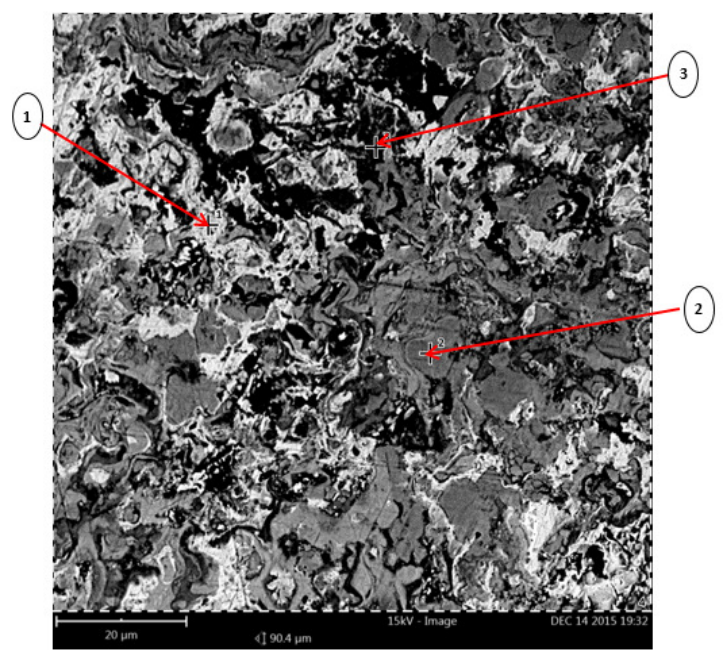

Fig. 8. The microstructure of $\mathrm{Cr} 3 \mathrm{C} 2-\mathrm{NiCr}$ coating before the test with three different spot for EDS analysis.

From Figure 10, it is observed that the red colour in element is chrome, the green colour in element is nickel and the blue colour in element is oxide splats. The presence of the oxide splats is due to the exposure of oxygen during thermal spraying process. Figure 11 shows that the spectrum of $\mathrm{Cr}_{3} \mathrm{C}_{2}-\mathrm{NiCr}$ coating before wear test The concentration of the Chrome element is the highest which is $55.2 \%$ and followed by the nickel and oxygen element which are $28.1 \%$ and $16.7 \%$, respectively. As supported by [1], the high volumes of carbides are well dispersed in the matrix which responsible for the higher micro hardness and lower porosity values in the $\mathrm{Cr}_{3} \mathrm{C}_{2}-\mathrm{NiCr}$ coating.

For the EDS analysis, Figure 12 shows the microstructure of $\mathrm{Cr}_{3} \mathrm{C}_{2}-\mathrm{NiCr}$ coating after the testing with different loads for three different spot for EDS analysis. The spot was randomly chosen in order to find the distribution of every element in the $\mathrm{Cr}_{3} \mathrm{C}_{2}-\mathrm{NiCr}$ coating.

Figure 13 shows the spectrum of every element in different spot at the top surface of $\mathrm{Cr}_{3} \mathrm{C}_{2}-\mathrm{NiCr}$ coating. The weight percentage of nickel and chrome at spot 1 is $71 \%$ and $29 \%$ while at the spot 2, the weight percentage of nickel and chrome are $77.1 \%$ and $22.9 \%$. At both spots, the weight percentage of nickel is high while at the spot 3 the weight percentage of nickel is about $40.9 \%$ and for the chrome, $59.1 \%$. Spots 1 and 2, are on the wear track while spot 3 is not. The chrome have been wear out at the spots 1 and 2 instead of the nickel. This been in contrast with ref. [1], states that micro hardness of chromium carbides is much higher than that of the NiCr matrix, so the carbides are more resistant to cutting or gouging than the matrix alloy phase.

The different concentration of $\mathrm{Cr}, \mathrm{Ni}$ and $\mathrm{O}$ after conducting wear testing with different loads based on the cut out map is illustrated in Figure 14. 

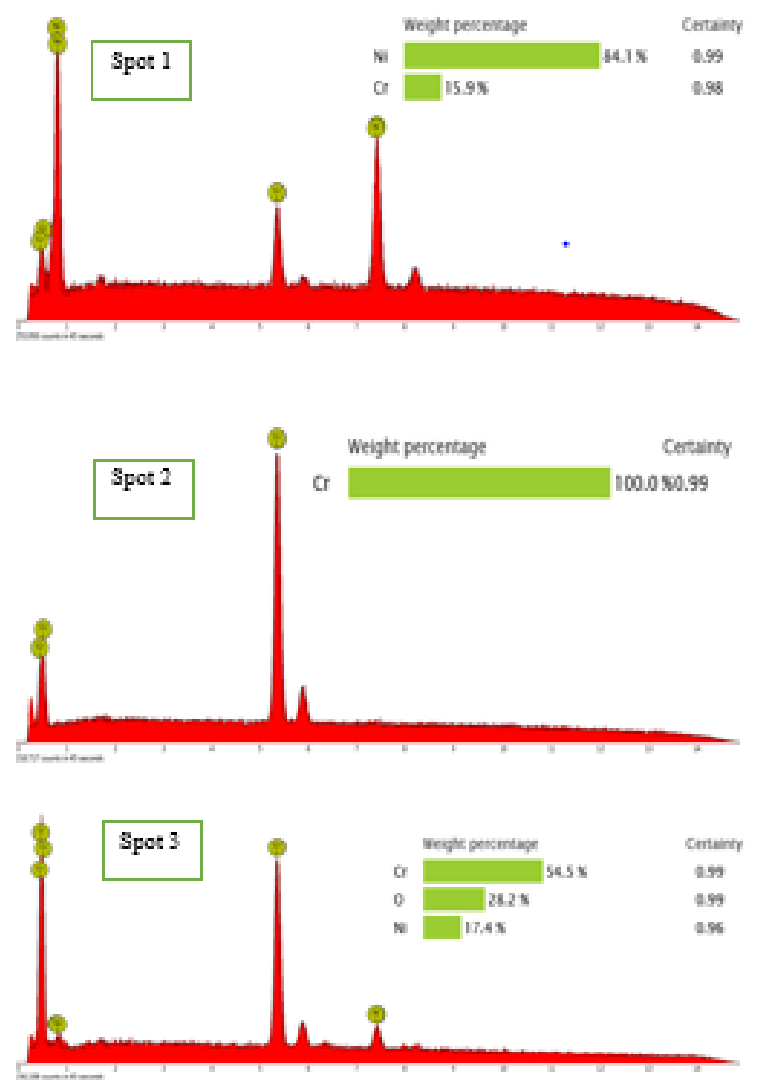

Fig. 9. The Spectrum of the three different spot.

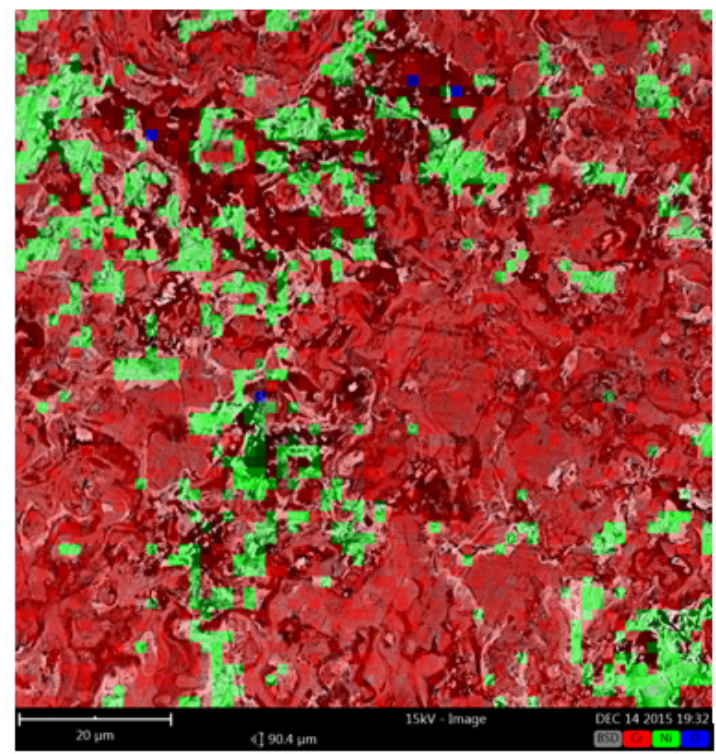

Fig. 10. The cut out map SEM-EDS analysis of $\mathrm{Cr} 3 \mathrm{C} 2-\mathrm{NiCr}$ coating before wear test. 


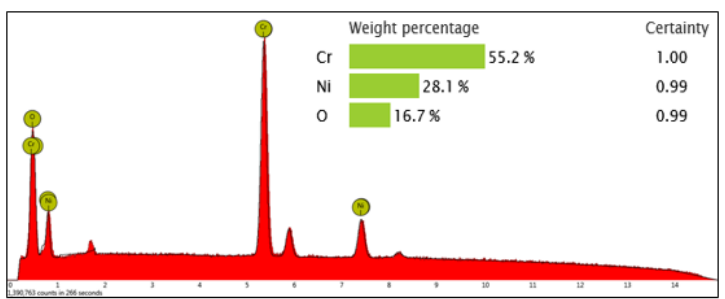

Fig. 11. The spectrum of $\mathrm{Cr} 3 \mathrm{C} 2-\mathrm{NiCr}$ coating before wear test.

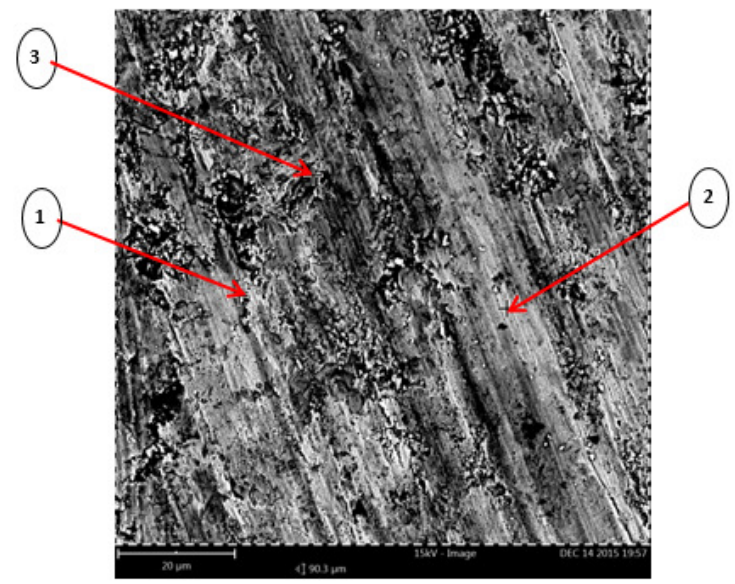

Fig. 12. $\mathrm{Cr} 3 \mathrm{C} 2-\mathrm{NiCr}$ coating after testing with different applied load.

Based on Figure 15, Ni has the highest weight percentage which is $42.4 \%$, followed by $\mathrm{Cr}$ and $\mathrm{O}$. However, the weight percentage difference between $\mathrm{Cr}$ and $\mathrm{Ni}$ is only $0.7 \%$ which is insignificant. The presence of oxygen is due to the formation of $\mathrm{Cr}_{2} \mathrm{O}_{3}$ layer during wear test. This is supported by [10], which stated that the coating worn surface was covered with oxides and claimed that a harder substrate is able to hold a thicker transfer layer of oxide more firmly as compared to softer one, which prevent the metal to metal contact and reduce the wear.

Figure 16 shows the $\mathrm{Cr}_{3} \mathrm{C}_{2}-\mathrm{NiCr}$ coating after being tested by different test duration. Three spots are randomly chosen as to identify the distributions of different elements of the coating namely $\mathrm{Cr}$ and $\mathrm{Ni}$. Meanwhile Figure 17 shows the spectrum for $\mathrm{Cr}_{3} \mathrm{C}_{2}-\mathrm{NiCr}$ coated sample after the wear test. The weight percentage of $\mathrm{Cr}$ and $\mathrm{Ni}$ in spot 1 are $33.8 \%$ and $66.2 \%$ respectively,. Nevertheless, spots 2 and 3 have higher concentration of $\mathrm{Cr}$ compared to $\mathrm{Ni}$; 96.9\% and 95.5\% respectively. The difference of concentration between $\mathrm{Cr}$ and $\mathrm{Ni}$ in these spots are significant, which can be concluded that $\mathrm{Cr}$ is more wear resistant than $\mathrm{Ni}$. 

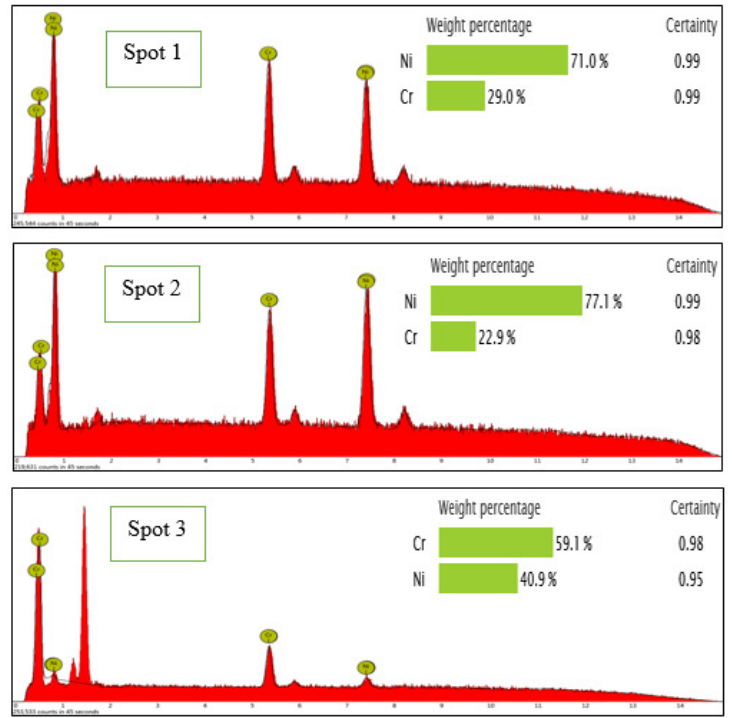

Fig. 13. The spectrum of $\mathrm{Cr} 3 \mathrm{C} 2-\mathrm{NiCr}$ coating after testing with different applied load.

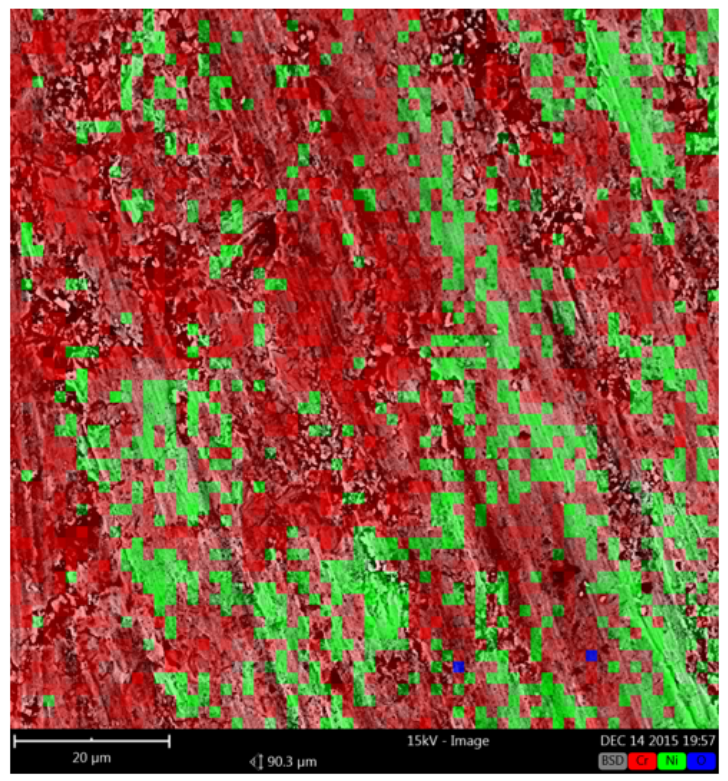

Fig. 14. The cut out map SEM-EDS analysis of $\mathrm{Cr} 3 \mathrm{C} 2-\mathrm{NiCr}$ coating after wear testing with different load.

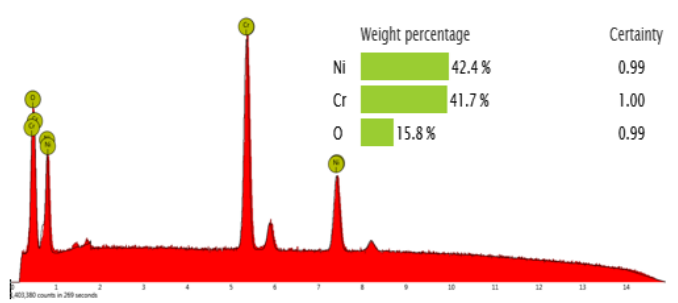

Fig. 15. The spectrum of $\mathrm{Cr} 3 \mathrm{C} 2-\mathrm{NiCr}$ coating after wear testing with different loads. 


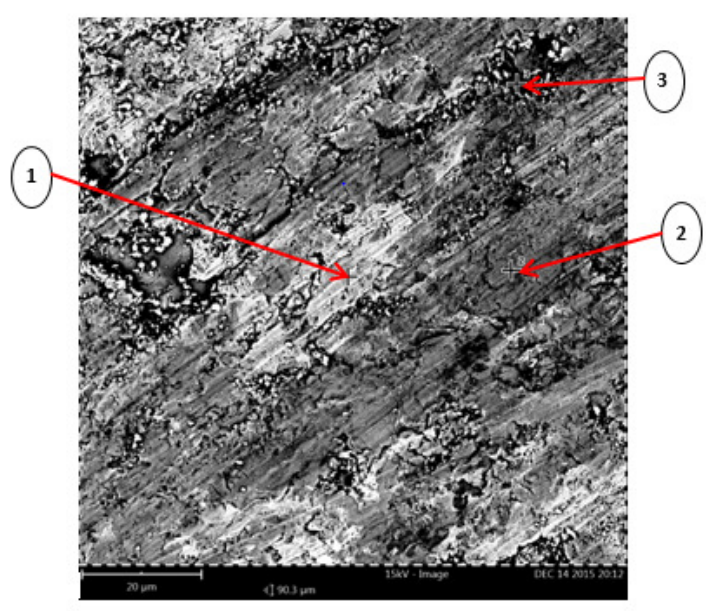

Fig. 16. $\mathrm{Cr} 3 \mathrm{C} 2-\mathrm{NiCr}$ coating after test with different cycles.
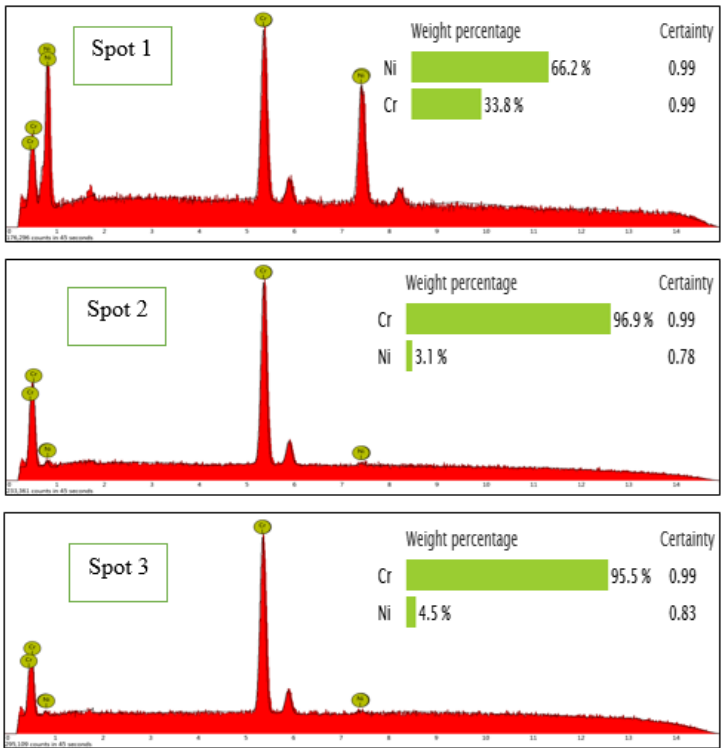

Fig. 17. The spectrum of $\mathrm{Cr} 3 \mathrm{C} 2-\mathrm{NiCr}$ coating after testing with different cycle times.

The different concentration of $\mathrm{Cr}, \mathrm{Ni}$ and $\mathrm{O}$ after conducting wear testing with different cycle times, based on the cut out map is illustrated in Figure 18. Based on Figure 19, $\mathrm{Cr}$ has the highest weight percentage which is $53.8 \%$, followed by $N i$ and $O$. The presence of oxygen is due to the formation of $\mathrm{Cr}_{2} \mathrm{O}_{3}$ layer during wear test. 


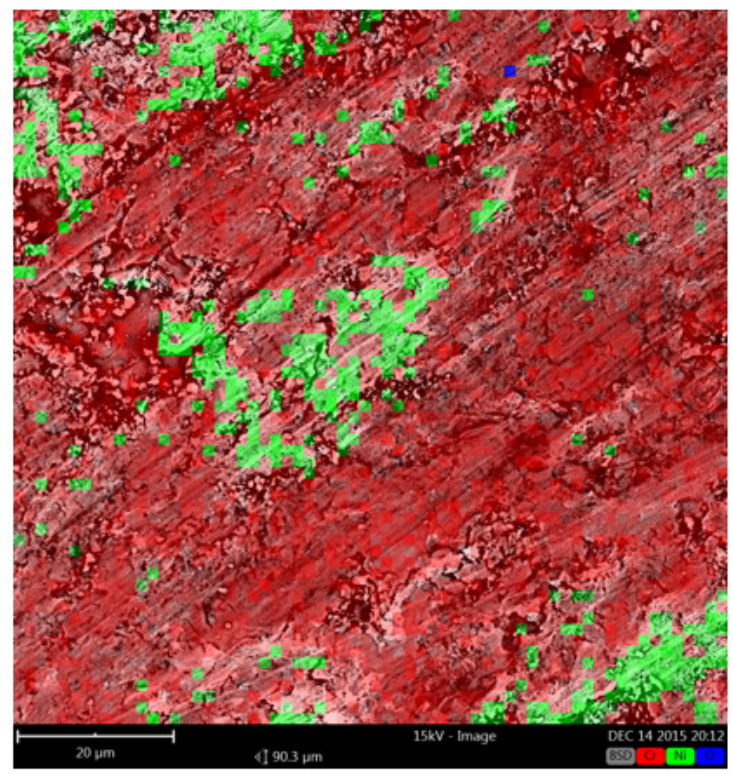

Fig. 18. The cut out map SEM-EDS analysis of $\mathrm{Cr} 3 \mathrm{C} 2-\mathrm{NiCr}$ coating after wear testing with different cycle times.

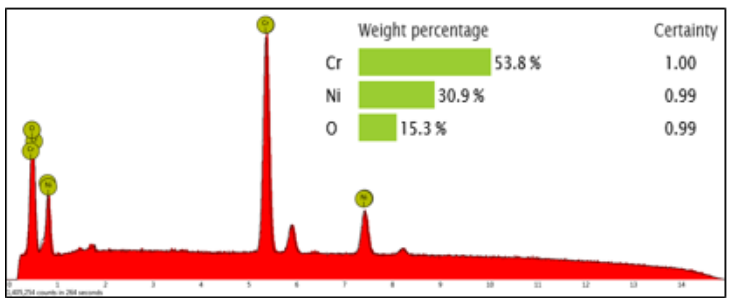

Fig. 19. The spectrum of $\mathrm{Cr} 3 \mathrm{C} 2-\mathrm{NiCr}$ coating after wear testing with different cycle times.

\section{Conclusions and recommendation}

Based on the analysis, several conclusions that can be deduced from this research, are:

- The lifetime prediction of the $\mathrm{Cr} 3 \mathrm{C} 2-\mathrm{NiCr}$ coating is estimated to be 2.11 years for $200 \mathrm{~g}$ weight loss and 8.5 years for testing at $350 \mathrm{~g}$.

- The lifetime prediction of $\mathrm{Cr} 3 \mathrm{C} 2-\mathrm{NiCr}$ coated pin is much higher than the uncoated pin.

- The percentage weight loss of $\mathrm{Cr} 3 \mathrm{C} 2-\mathrm{NiCr}$ coated pin is lower than uncoated pin for every different loads and total times of wear test.

- The wear resistance of the $\mathrm{Cr} 3 \mathrm{C} 2-\mathrm{NiCr}$ coated pin is significantly higher than uncoated pin.

- The microstructure of $\mathrm{Cr} 3 \mathrm{C} 2-\mathrm{NiCr}$ coated pin confirmed the low porosity thermal spray coating by HVOF process. Wear tracks on the coating were smooth with no visible crack and load was determined as the factor affecting wear rate more than the number of cycles. 
The authors were grateful for the funding received from the Ministry of Higher Education (MOHE), Malaysia under the Fundamental Research Grant Scheme (FRGS).

\section{References}

1. M. A. Zavareh, A. A. D. M. Sarhan, B. B. Razak, and W. J. Basirun, Ceram. Int., 41, pp. 5387-5396 (2015)

2. V. P. Singh, A. Sil, and R. Jayaganthan, Mater. Design, 32, pp. 584-591 (2011)

3. J. Picas, A. Forn, A. Igartua, and G. Mendoza, Surf. Coat. Tech., 174, pp. 1095-1100 (2003)

4. H. Zhu, Q. Zhu, A. K. Tieu, B. Kosasih, and C. KongWear, 302, pp. 1310-1318 (2013)

5. R. Pileggi, M. Tului, D. Stocchi, and S. Lionetti, Surf. Coat. Tech., 268, pp. 247-251 (2015)

6. M. Mohanty, R. Smith, M. De Bonte, J.-P. Cells, and E. LugscheiderWear, 198, pp. 251266 (1996)

7. Y. Ishikawa, S. Kuroda, J. Kawakita, Y. Sakamoto, and M. Takaya, Surf. Coat. Tech., 201, pp. 4718-4727 (2007)

8. Advance Coating. (2015, $30 \mathrm{July).} \mathrm{HVOF} \mathrm{spray} \mathrm{process} \mathrm{(High} \mathrm{Velocity} \mathrm{Oxygen} \mathrm{Fuel).}$ Available: http://www.advanced-coating.com/english/spraying-hvof.htm

9. J. Wang, L. Zhang, B. Sun, and Y. Zhou, Surf. Coat. Tech., 130, pp. 69-73 (2000)

10. H. S. Sidhu, B. S. Sidhu, and S. Prakash, Tribol. Int., 43, pp. 887-890 (2010) 